Actta Theriologica 43 (3): 263-270, 1998.

PL IISSN 0001-7051

\title{
Reproductive behaviour of the South Indian gerbil Tatera indica cuvieri with a note on the role of postejaculatory copulations
}

\author{
Biju B. THOMAS and Mathew M. OOMMEN
}

\begin{abstract}
Thomas B. B. and Oommen M. M. 1998. Reproductive behaviour of the South Indian gerbil Tatera indica cuvieri with a note on the role of postejaculatory copulations. Acta Theriologica 43: 263-270.

The reproductive behaviour of Tatera indica cuvieri (Waterhouse, 1838) has been evaluated in detail. It involves 1 to 4 series, with each series composed of mounts, intromissions, and ending up with ejaculation. Quantitative measures of the copulatory behavioural variables indicate significant difference across the 4 series. While intromission duration and thrust frequency progressively increased across the 4 series, significant decrease was observed regarding postejaculatory interval. After the final ejaculation, the male resorted to a state of continued copulatory activity, referred to as postejaculatory copulation (PEC). Higher levels of copulatory activity are observed during this phase as evidenced by increases in total number of intromissions, duration of intromissions and thrust frequency. Further, the postejaculatory copulation is of considerable significance in inducing pregnancy in females, the chance of pregnancy being higher if the female is subjected to PEC.

Department of Zoology, University of Kerala, Kariavattom 695 581, Trivandrum, Kerala State, India

Key words: Tatera indica cuvieri, copulatory behaviour, postejaculatory copulation, pregnancy
\end{abstract}

\section{Introduction}

The drive to reproduce is one of life's strongest imperatives. This is accomplished by adult male and female behavioural patterns that have evolved to ensure fertilization and survival of the young. Reproductive behaviour is initiated with courtship as a prelude to mating followed by copulatory activity, and comprises several behavioural responses, for which sexual motivation is responsible (Vega and Larsson 1993). Copulatory behaviour is highly diversified, especially among different species of rodents (Dewsbury 1978), and sets up the adequate condition necessary for fertilisation and subsequent pregnancy (Toner and Adler 1986, Toner et al. 1987). Several neuroendocrine and behavioural processes are activated by copulatory vaginal stimulation (Erskine et al. 1989, Clendenon and Rissman 1990, Fortune et al. 1992). 
Reproductive behavioural variables have physiological implications. Intromission and ejaculation are the part of an arousal system whereas events like postejaculatory interval comprises an inhibitory process (Sachs and Barfield 1976). Further, the intromission frequency and intromission duration are indices of amount of stimulation needed for ejaculation.

The high population density and abundant species diversity, characteristic of tropical environment, are obviously the result of efficient reproductive mechanisms. Among tropical animals, rodents are a significant group of smaller mammals; a majority of them have a pest status. However, information regarding the reproductive phenomena of tropical rodents is scant. Tatera indica cuvieri (Waterhouse 1838) is a burrow dwelling rodent having the status of a pest of food crops. The adults of this species exhibit a clear cut diversity in burrow occupancy with the male living separately and the female living with youngones (Thomas and Oommen 1997). Hence the present study on the reproductive behaviour of this rodent was taken up, to obtain a better insight into the reproductive phenomena of tropical rodents.

\section{Material and methods}

Gerbils were collected from the field, brought to the laboratory, housed in cement tanks and maintained on a diet of tapioca or soaked chick pea prior to acclimatisation. Gradually this diet was replaced by standard laboratory rat food, with water provided ad libitum. Healthy animals were separated and maintained in individual wire mesh cages $(45 \times 30 \times 30 \mathrm{~cm})$ under ambient temperature and photoperiod, and fed once daily between 16.00 and $18.00 \mathrm{hr}$. After 30 days of acclimatisation to the laboratory conditions, routine monitoring of reproductive cyclicity of females (weighing ca 150 g) on the basis of vaginal smears, taken daily between 10.00 and $11.00 \mathrm{hr}$, were commenced. The smears were stained (Giemsa stain) and the different estrous phases ascertained based on the descriptions of Tienhoven (1968). The four cyclic stages, namely proestrus, estrus, metestrus and diestrus are observable in this species. The females were found to be receptive during the early dark phase when the animal is at the end of proestrus. The receptivity were ascertained by their lordotic response to a male for which, the females in late proestrus were introduced to a sexually experienced male in a cage. The female responded to male mountings by the lordotic feature of elevation of head and perineal region giving rise to concaving of the spine. Only those females showing regular cycles and lordotic response to experimental males, were employed for evaluating the reproductive behaviour. Adult males (160-190 g) were selected and used for the mating tests. Behavioural observations were carried out under red light from $20.00 \mathrm{hr}$ onwards after introducing the receptive female into the male cage. The entire copulatory period is divided into two phases, phase I and phase II. Phase I comprises of the various copulatory behavioural patterns from the moment the female was introduced into the male cage, up to the end of the last postejaculatory interval. Phase II includes details of the copulatory behavioural patterns exhibited exclusively during the postejaculatory copulations or PEC.

As the animal copulates in a way that the observer gets enough time to discriminate between various activities, the copulatory activity of gerbils were recorded manually using pen and paper with the aid of a digital stop watch. Repeated non-experimental examination of the motor mating patterns were conducted earlier, which include ventral view observations to confirm the various copulatory behavioural patterns. 


\section{Evaluation of basic reproductive behaviour}

Ten reproductive behavioural variables, which could be of importance for evaluating the basic motor patterns of rodents, as per the descriptions by Beach and Jordan (1956) Sachs and Barfield (1974) Gray and Dewsbury (1975) and Pospichal et al. (1991) and also on the basis of preliminary observations, were taken into consideration. The variables are: number of intromissions (NI) - total number of intromissions, duration of intromissions (DI) - time taken for intromissions, ejaculation frequency $(\mathrm{EF})$ - number of ejaculations, thrust frequency (TF) - number of intravaginal thrusts, thrust per intromission (T/I) - mean number of intravaginal thrusts during each intromission, mean intromission duration (MID) - mean duration of intromissions, interintromission interval (III) - mean interval between successive intromissions, postejaculatory interval (PEI) - time from the end of the ejaculatory intromission to the first intromission of the next ejaculatory series, ejaculation latency (EL) - time between the first intromission and subsequent ejaculation in a series, mount per intromission $(\mathrm{M} / \mathrm{I})$ - number of mounts divided by the number of intromissions.

Measures were taken from the time at which instance the female was introduced into the male cage until the attainment of 'satiety' criterion of 60 minutes without intromission after an ejaculation; or 15 minutes without intromissions during phase II. If a male failed to achieve intromission within one hour after introduction of the female, further observations were stopped. On the other hand, if it achieved intromission during this period, observations were continued; and if no ejaculation occurred durng the next 30 minutes, then again the observations were discontinued.

All the temporal and frequency based observation recordings were logged in a computer using common data entry packages. The quantitative measures of the selected behavioural variables were obtained as computer processed output for further statistical analysis.

In total, 31 male gerbils which were found to be reproductively active in pre-experimental trials, and 30 females showing regular estrous cycles and lordotic response were employed for mating tests. Eacı male was subjected to 3 mating tests, and it was ensured that the same female was never exposed to the same male twice and that at least a one week interval was given during each of the 3 tests.

Variables belonging to the respective series of phase I and phase II were then grouped together, and possible significant difference among them across series, and phase II were analysed using ANOVA.

\section{Postejaculatory copulations and pregnancy in females}

To ascertain the significance of postejaculatory copulation (PEC) for their possible role in inducing prennancy, the females were subjected to the following mating conditions and its outcome evaluated: grotp I - received one ejaculation, group II - received one ejaculation followed by postejaculatory coptlatory activity, group III - received two ejaculations, group IV - received two ejaculations followed by postejaculatory copulatory activity, group V - received 3 ejaculations, group VI - received 3 ejiculations followed by postejaculatory copulatory activity.

After each test, females were examined for pregnancy success based on their vaginal smear and grouped as non-pregnant, pseudopregnant and pregnant. The data thus obtained were statistically anaysed with test for proportion, for pairwise comparisons.

\section{Results}

\section{Basic reproductive behaviour}

Quantitative measures of the 9 mating variables are given in Table 1 . No significant changes in number of intromissions (NI) could be observed across the fou series of phase I. However, number of intromissions (NI) was found to be high during phase II. Significant differences across series, and phase II, are also 
Table 1. Quantitative measures (mean $\pm \mathrm{SE}$ ) of the temporal and frequency variables of mating in Tatera indica cuvieri. ${ }^{*}$ - significance at $p<0.01$ (One way ANOVA), ns - not significant, $\dagger-$ values are in seconds.

\begin{tabular}{|c|c|c|c|c|c|c|c|c|}
\hline \multicolumn{2}{|c|}{$\begin{array}{l}\text { Measures } \\
\text { number of males: } \\
\text { number of measurements: }\end{array}$} & $\begin{array}{c}\text { Series } 1 \\
31 \\
93\end{array}$ & $\begin{array}{c}\text { Series } 2 \\
26 \\
72\end{array}$ & $\begin{array}{c}\text { Series } 3 \\
13 \\
34\end{array}$ & $\begin{array}{c}\text { Series } 4 \\
5 \\
9\end{array}$ & $\begin{array}{l}\text { Phase II } \\
26 \\
70\end{array}$ & $\begin{array}{l}F \text { value } \\
\text { (excluding } \\
\text { phase II) }\end{array}$ & $\begin{array}{l}F \text { value } \\
\text { (including } \\
\text { phase II) }\end{array}$ \\
\hline NI & $\begin{array}{l}\text { Number of } \\
\text { intromissions }\end{array}$ & $\begin{array}{r}5.63 \\
\pm 0.23\end{array}$ & $\begin{array}{r}4.97 \\
\pm 0.31\end{array}$ & $\begin{array}{r}6.38 \\
\pm 1.34\end{array}$ & $\begin{array}{r}5.00 \\
\pm 1.30\end{array}$ & $\begin{array}{r}20.64 \\
\pm 0.70\end{array}$ & $1.19^{\mathrm{ns}}$ & $36.41^{*}$ \\
\hline $\mathrm{DI}^{\dagger}$ & $\begin{array}{l}\text { Duration of } \\
\text { intromissions }\end{array}$ & $\begin{array}{r}45.88 \\
\pm 2.18\end{array}$ & $\begin{array}{r}46.00 \\
\pm 2.78\end{array}$ & $\begin{array}{r}87.79 \\
\pm 22.41\end{array}$ & $\begin{array}{r}65.83 \\
\pm 14.30\end{array}$ & $\begin{array}{r}318.52 \\
\pm 2.75\end{array}$ & $5.70^{*}$ & $52.10^{*}$ \\
\hline $\mathrm{III}^{\dagger}$ & $\begin{array}{l}\text { Inter intromission } \\
\text { interval }\end{array}$ & $\begin{array}{r}88.45 \\
\pm 10.44\end{array}$ & $\begin{array}{r}53.66 \\
\pm 7.62\end{array}$ & $\begin{array}{r}72.89 \\
\pm 8.99\end{array}$ & $\begin{array}{r}156.92 \\
\pm 51.05\end{array}$ & $\begin{array}{r}205.30 \\
\pm 2.21\end{array}$ & $4.75^{*}$ & $22.24^{*}$ \\
\hline $\mathrm{PEI}^{\dagger}$ & $\begin{array}{l}\text { Postejaculatory } \\
\text { interval }\end{array}$ & $\begin{array}{r}2209.53 \\
\pm 121.00\end{array}$ & $\begin{array}{l}1800.52 \\
\pm 117.40\end{array}$ & $\begin{array}{r}1619.42 \\
\pm 178.34\end{array}$ & $\begin{array}{r}1443.17 \\
\pm 432.33\end{array}$ & $\begin{array}{l}\text { variable } \\
\text { absent }\end{array}$ & $3.73^{*}$ & - \\
\hline $\mathrm{TF}$ & Thrust frequency & $\begin{array}{r}21.85 \\
\pm 0.82\end{array}$ & $\begin{array}{r}24.16 \\
\pm 1.73\end{array}$ & $\begin{array}{r}46.50 \\
\pm 11.75\end{array}$ & $\begin{array}{r}37.67 \\
\pm 11.95\end{array}$ & $\begin{array}{r}163.95 \\
\pm 15.69\end{array}$ & $6.76^{*}$ & $60.59^{*}$ \\
\hline $\mathrm{T} / \mathrm{I}$ & $\begin{array}{l}\text { Thrust per } \\
\text { intromission }\end{array}$ & $\begin{array}{r}4.15 \\
\pm 0.15\end{array}$ & $\begin{array}{r}5.18 \\
\pm 0.26\end{array}$ & $\begin{array}{l}7.4 \\
\pm 0.71\end{array}$ & $\begin{array}{r}6.93 \\
\pm 0.78\end{array}$ & $\begin{array}{r}8.47 \\
\pm 0.41\end{array}$ & $32.32 *$ & $20.17^{*}$ \\
\hline $\mathrm{MID}^{\dagger}$ & $\begin{array}{l}\text { Mean intromission } \\
\text { duration }\end{array}$ & $\begin{array}{r}8.77 \\
\pm 0.45\end{array}$ & $\begin{array}{r}9.82 \\
\pm 0.45\end{array}$ & $\begin{array}{r}14.17 \\
\pm 1.07\end{array}$ & $\begin{array}{r}15.46 \\
\pm 3.01\end{array}$ & $\begin{array}{r}16.35 \\
\pm 0.77\end{array}$ & $14.05^{*}$ & $26.64^{*}$ \\
\hline $\mathrm{EL}^{\dagger}$ & Ejaculation latency & $\begin{array}{r}631.97 \\
\pm 81.21\end{array}$ & $\begin{array}{r}248.26 \\
\pm 47.45\end{array}$ & $\begin{array}{r}351.04 \\
\pm 81.75\end{array}$ & $\begin{array}{r}635.50 \\
\pm 276.61\end{array}$ & $\begin{array}{l}\text { variable } \\
\text { absent }\end{array}$ & $5.72 *$ & - \\
\hline $\mathrm{M} / \mathrm{I}$ & $\begin{array}{l}\text { Mount per } \\
\text { intromission }\end{array}$ & $\begin{array}{r}1.58 \\
\pm 0.15\end{array}$ & $\begin{array}{r}1.19 \\
\pm 0.05\end{array}$ & $\begin{array}{r}1.16 \\
\pm 0.05\end{array}$ & $\begin{array}{r}2.36 \\
\pm 1.33\end{array}$ & $\begin{array}{r}1.19 \\
\pm 0.28\end{array}$ & $3.49 *$ & $3.69^{*}$ \\
\hline
\end{tabular}

observable with regard to duration of intromissions (DI), suggesting that as the mating proceeded, duration of intromissions increased. This is further evidenced by the increase in the mean intromission duration (MID) across the series.

Thrust frequency (TF) and its related variable, thrust per intromission (T/I), progressively increased across series with a marked change in phese II.

Though interintromission interval (III) is relatively high in series 1 when compared with the remaining series and phase II, a progressive increase occurred only from series 2 onwards including phase II. The situation was also applicable in the case of ejaculation latency (EL). However, regarding postejaculatory interval (PEI), significant decrease was observed across the 4 series.

The mount/intromission (M/I) was higher for the first series and the fourth series only.

\section{Postejaculatory copulations and pregnancy in females}

Table 2 shows the data on the outcome of the pregnancy, pseudopregnancy and regular cyclicity of the females subjected to the different mating conditions. Statistical analysis employing test for proportion for each mating conditions in all 
Table 2. Percentages of pregnant, pseudopregnant and normal cycling proportions of female Tatera indica cuvieri subjected to different mating conditions. $n$-number of females under each condition.

\begin{tabular}{|c|c|c|c|c|}
\hline Condition & $n$ & Pregnancy & $\begin{array}{c}\text { Pseudo- } \\
\text { pregnancy }\end{array}$ & Cycling \\
\hline Single ejaculation & 26 & 8 & 8 & 84 \\
\hline Single ejaculation + Postejaculatory copulation & 6 & 33 & 50 & 17 \\
\hline Two ejaculations & 15 & 27 & 6 & 67 \\
\hline Two ejaculations + Postejaculatory copulation & 11 & 46 & 18 & 36 \\
\hline Three ejaculations & 8 & 62 & 13 & 25 \\
\hline Three ejaculations + Postejaculatory copulation & 20 & 60 & 5 & 35 \\
\hline
\end{tabular}

Table 3. Mating conditions under which significant differences in the pregnancy was observed, based on test for proportion. PEC Postejaculatory copulation, ej - ejaculation.

\begin{tabular}{lcc}
\hline Condition & $Z$ & $p$ \\
\hline 1 ej $\times 2$ ej + PEC & 2.68 & $<0.003$ \\
1 ej $\times 3$ ej & 3.35 & $<0.001$ \\
1 ej $\times 3$ ej + PEC & 3.75 & $<0.001$ \\
2 ej $\times 3$ ej + PEC & 1.96 & $<0.025$ \\
\hline
\end{tabular}

the probable combinations, reveal significant relations between mating conditions and pregnancy success (Table 3).

\section{Discussion}

In Tatera indica cuvieri male reproductive behaviour starts with the stimulus from the receptive female eliciting sexual motivation leading to courtship. Courtship increases arousal in the male until copulatory threshold is reached, when male starts mounting (Sachs and Barfield 1976). The mounting may lead to intromissions, providing vaginal stimulation in the female thereby increasing the excitatory value needed for the male to ejaculate. After a period of rest (postejaculatory interval or PEI) copulatory activity is resumed, the pattern being repeated for several successive copulations. Over the complete sequence of reproductive behaviour, $T$. indica cuvieri exhibited an average of 2.2 ejaculations (range 1-4). Based on distinct features namely, lock, intravaginal thrusts, intromissions and multiple ejaculations, Dewsbury (1978) has described 16 possible copulatory patterns among rodents, and in general the copulatory pattern of Tatera indica cuvieri can be considered to be of pattern 9 which is characterised by the absence of lock and presence of intravaginal thrusts, multiple intromission and ejaculations. 
Multiple intromissions with pelvic thrusts are characteristic for all ejaculations in $T$. indica cuvieri. Quantitative measures of the reproductive behaviour of $T$. indica cuvieri can be broadly divided into two phases; phase I comprising several series with each series involving mount, intromission, and ejaculation. After phase I the male enters to phase II (postejaculatory copulation or PEC). Across the different series a progressive increase for mean intromission duration (MID), duration of intromissions (DI), interintromission interval (III), thrust frequency (TF) and thrust per intromission (T/I) is observed. Of these measures, DI, MID, $\mathrm{TF}$ and $\mathrm{T} / \mathrm{I}$ are indicative of copulatory vaginal stimulation. Duration of intromissions (DI) is considered as a measure of excitatory value needed for ejaculatory threshold (Sachs and Barfield 1976). Quite probably the excitatory value required for ejaculatory threshold increases across series. Number of intromissions (NI), another common index of the stimuli requisite for ejaculation (Sachs and Barfield 1976), does not show significant difference across four copulatory series. However, laboratory rats show a progressive decrease in number of intromission across the series (Austin and Dewsbury 1986).

Postejaculatory interval (PEI) is reflective of an inhibitory mechanism that can be measured independently of the excitation process (Sachs and Barfield 1976). In $T$. indica cuvieri, PEI is found to be progressively decreasing across the series. This decrease probably indicate a lowering of an inhibitory process, thereby leading to the postejaculatory copulatory activity (PEC) and might be significant for pregnancy. However, among other rodents including Mongolian gerbils (Burley 1980 ) and meadow voles (Gray and Dewsbury 1975) there is a progressive increase in the postejaculatory interval.

Higher ejaculation latency, observed during the first series may be a reflection of higher interintromission interval (III); generally observed between the first two intromissions of the first series. The increase in $\mathrm{M} / \mathrm{I}$ observed in the fourth series, however, may either be due to the lack of co-operation from the part of females or inability of the male to achieve intromission as satiety approaches.

Continued copulatory activity, which Dewsbury (1985) refers to as postejaculatory copulation, after the last series is a notable feature of the reproductive behaviour of this species (Tatera indica cuvieri). The copulatory behavioural variables including the number of intromissions, duration of intromissions and thrust frequency are significantly higher during phase II (continued copulatory activity or PEC) when compared with phase I. Phase I and phase II significantly differ with regard to interintromission interval (III), mean intromission duration (MID), thrust per intromission (T/I) and mount/intromission ratio (M/I). Prolonged copulatory activity such as PEC has been attributed as part of high stimulus requirements of the females (Dewsbury and Estep 1975).

The prolonged copulatory activity can have several functions. It may enable a male to effectively stall the females from mating access to other males (Marion and Hunter 1993), or decrease the duration of estrus as reported among hamsters (Huck et al. 1987) and rats (Erskine et al. 1989). Further it may prevent fertili- 
zation by other males, as in golden hamsters (Huck et al. 1989), deer mice (Dewsbury et al. 1987), roof rats (Estep 1988) and laboratory rats (McClintock et al. 1982, Moore and Wong 1992). In T. indica cuvieri the female confronts the possibility of multiple male matings in her natural habitat (Thomas and Oommen 1997). As the male is in physical contact with the female during PEC, the chance of another male mating with the same female is lesser, there by exhibiting a kind of mate guarding as described among insects by Parker (1970).

The incidence of pregnancy among the females of Tatera indica cuvieri subjected to different mating conditions clearly show that the chance of pregnancy is related with the number of ejaculations including the pre-ejaculatory intromissions (Table 2). Earlier Dewsbury (1978) had illustrated a relationship between the number of ejaculatory series and the incidence of pregnancy. While species such as Microtus montanus, Microtus agrestis, Mesocricetus auratus, Meriones tristrami, and Peromyscus gossypinus exhibit an increase in the incidence of pregnancy as a result of subsequent ejaculations, Microtus ochrogaster and Rattus rattus exhibit no such relationship. In laboratory rats, this phenomena depends on age, and/or parity. In $T$. indica cuvieri those females subjected to more ejaculatory series had better probability for pregnancy attainment.

Apart from number of ejaculations, adequate quantities of postejaculatory copulation also seem to promote the pregnancy of the females in T. indica cuvieri. This is evident from the fact that no statistically significant differences in pregnancies occurred between one ejaculation group and two ejaculation group, whereas significant difference is observed when one ejaculation group was compared with two ejaculation plus postejaculatory copulation (PEC) group. Similarly, no significant differences are observed when two ejaculation group and three ejaculation group are compared; however, significant differences are discernible when two ejaculation group is compared with three ejaculation group coupled with PEC. Similar role of postejaculatory copulation in promoting the incidence of pregnancy has also been reported for cactus mice by Dewsbury and Estep (1975). It may also be added that PEC observed in $T$. indica cuvieri can have endocrine and neuroendocrine attributes related with better chance of pregnancy.

\section{References}

Austin D. and Dewsbury D. A. 1986. Reproductive capacity of male laboratory rats. Physiology and Behavior 37: 627-632.

Beach F. A. and Jordan L. 1956. Sexual exhaustion and recovery in the male rat. Quarterly Journal of Experimental Psychology 8: 121-133.

Burley R. A. 1980. Pre-copulatory and copulatory behaviour in relation to stages of the oestrous cycle in the female Mongolian gerbil. Behaviour 70: 211-240.

Clendenon A. L. and Rissman E. F. 1990. Prolonged copulatory behaviour facilitates pregnancy success in the musk shrew. Physiology and Behavior 47: 831-835. 
Dewsbury D. A. 1978. The comparative method in studies of reproductive behaviour. [In: Sex and behaviour. T. E. Mc Gill, D. A. Dewsbury and B. D. Sachs, eds]. Pleneum Press, New York: 83-112

Dewsbury D. A. 1985. Interactions between males and their sperm during multi-male copulatory episodes of deer mice (Peromyscus maniculatus). Animal Behaviour 33: 1266-1274.

Dewsbury D. A. and Estep D. Q. 1975. Pregnancy in cactus mice: effects of prolonged copulation. Science 187: 552-553.

Dewsbury D. A. Shapiro L. E. and Taylor S. A. 1987. Disruption of ejaculates by male competition in deer mice (Peromyscus maniculatus). Physiology and Behavior 41: 53-58.

Erskine M. S., Kornberg E. and Cherry J. A. 1989. Paced copulation in rats: effects of intromission frequency and duration on luteal activation and estrous length. Physiology and Behavior 45: 33-39.

Estep D. Q. 1988. Copulations by other males shorten the post-ejaculatory intervals of pairs of roof rats, Rattus rattus. Animal Behaviour 36: 299-300.

Fortune J. E., Eppig J. J. and Rissman E. F. 1992. Mating stimulates estradiol production by ovaries of the musk shrew (Suncus murinus). Biology of Reproduction 6: 885-891.

Gray G. D. and Dewsbury D. A. 1975. A quantitative description of the copulatory behaviour of meadow voles (Microtus pennsylvanicus). Animal Behaviour 23: 261-267.

Huck U. W., Lisk R. D., Parente E. J. and Guyton C. L. 1987. Mating-induced inhibition of receptivity in the female golden hamster (Mesocricetus auratus): III. stimuli mediating long term effects. Physiology and Behavior 39: 421-428.

Huck U. W., Tonias B. A. and Lisk R. D. 1989. The effectiveness of competitive male inseminations in golden hamsters, Mesocricetus auratus depends on an interaction of mating order, time delay between males, and the time of mating relative to ovulation. Animal Behaviour 37: 674-680.

Marion P. and Hunter F. M. 1993. Intraspecific variation in courtship and copulation: an effect of mismatch in partner attractiveness? Behaviour 127: 265-277.

McClintock M. K., Anisko J. J. and Adler N. T. 1982. Group mating among Norway rats II. The social dynamics of copulation: competition, co-operation and mate choice. Animal Behaviour 30: 410-425.

Moore C. L. and Wong L. 1992. Copulatory behaviour, reproduction, and sperm competition in two strains of male rats. Physiology and Behavior 51: 569-573.

Parker G. A. 1970. Sperm competition and its evolutionary consequences in the insects. Biological Review 45: 525-567.

Pospichal M. W., Karp J. D. and Powers J. B. 1991. Influence of day length on male hamster sexual behaviour: masking effects of testosterone. Physiology Behavior 49: 417-422.

Sachs B. D. and Barfield R. J. 1974. Copulatory behavior of male rats given intermittent electric shocks, theorotical implications. Journal of Comparative Physiology and Psychology 86: 607-615.

Sachs B. D. and Barfield R. J. 1976. Functional analysis of masculine copulatory behavior in the rat. [In: Advances in the study of behavior, J. S. Rosenblatt, R. A. Hinde, E. Shaw and C. Beer, eds]. Academic press, New York, Vol. 7: 91-154.

Thomas B. B. and Oommen M. M. 1997. Male, female burrow occupancy pattern of the South Indian gerbil Tatera indica cuvieri. Journal of The Bombay Natural History Society 94: 149-151.

Tienhoven A. V. 1968. Reproductive physiology of vertebrates. Saunders Company, London: 1-498.

Toner J. P. and Adler N. T. 1986. The pre-ejaculatory behavior of male and female rats affects the number of sperm in the vagina and uterus. Physiology and Behavior 36: 363-367.

Toner J. P; Attas A. I. and Adler N. T. 1987. Transcervical sperm transport in the rat: the role of pre-ejaculatory behaviour and copulatory plug fit. Physiology and Behavior 39: 371-375.

Vega M. J. and Larsson K. 1993. Sexual orientation and sexual motivation of the adult male rat. Physiology and Behavior 53: 747-750.

Received 16 April 1997, accepted 31 December 1997. 